\title{
АКТУАЛЬНОСТЬ СТОМАТОЛОГИЧЕСКОГО ПРОСВЕЩЕНИЯ ЛИЦ ПЕНСИОННОГО ВОЗРАСТА В СЕЛЬСКОЙ МЕСТНОСТИ
}

\section{RELEVANCE OF DENTAL EDUCATION OF PERSONAL AGE PERSONS IN RURAL AREAS}

T. Zubkova

Summary. Today, dentistry is one of the fastest growing branches of medicine. Modern materials and working methods allow us to provide high-quality and effective assistance. However, in our country, an annual increase in dental morbidity is noted. For many reasons, people of retirement age are particularly vulnerable in this regard. An analysis of the work performed showed that $53 \%$ of the patients surveyed had a question about removable prosthetics by the time they reached retirement age. Inspections carried out confirmed the fact of poor oral hygiene and the need for rehabilitation. A certain role in such indicators is given to the dental illiteracy of the population. Today, the dentist is faced with the task not only in providing quality treatment, but also in conducting educational work with patients.

Keywords: dental education, Sanitary-educational work, dental health, retirement age.

\author{
Зубкова Татьяна Владимировна \\ Аспирант, Воронежский государственный \\ медицинский университет им. Н. Н. Бурденко \\ tatjana-zubkova00@yandex.ru
}

Аннотация. Сегодня стоматология является одной из самых быстро развивающихся отраслей медицины. Современные материалы и методы работы позволяют оказывать качественную и эффективную помощь. Однако в нашей стране ежегодно отмечается рост стоматологической заболеваемости. В силу многих обстоятельств особо уязвимы В этом отношении люди пенсионного возраста. Проведенный анализ выполненных работ показал, что у 53\% опрошенных пациентов, к моменту наступления пенсионного возраста стоял вопрос о съемном протезировании. Проведенные осмотры подтверждали факт неудовлетворительной гигиены полости рта и необходимость санации. Определенную роль в таких показателях отводится стоматологической неграмотности населения. На сегодняшний день перед врачом-стоматологом стоит задача не только в оказании качественного лечения, но и в проведении санитарно-просветительской работы с пациентами.

Ключевые слова: стоматологическое просвещение, Санитарно-просветительская работа, стоматологическое здоровье, пенсионный возраст.

ротовой полости, несвоевременное и некачественное лечение, плохо выполненные зубные протезы в совокупности снижают качество жизни пациента, то есть влияют на его здоровье в целом.

Многочисленные исследования, проведенные за последние годы, подтверждают то факт, что у пациентов пожилого и старческого возраста, в большинстве случаев неудовлетворительное состояние ротовой полости. Сюда смело можно отнести и некариозные поражения твердых тканей зубов, и парадонтологические заболевания, возникающие на фоне хронических общесоматических патологий и приема лекарственных средств, кариес в различных его проявлениях, зачастую приводящий к полной потере зуба (в силу возраста, большинство пациентов пенсионного возраста, предпочитают не лечить кариес, допуская в дальнейшем удаление зуба целенаправленно), утрата зубов по различным причинам с течением времени (у лиц пожилого возраста эта проблема выходит на первое место). Отсутствие зубов опосредовано ведет к функциональным нарушениям и расстройствам жевательного аппарата, что, безусловно, усугубляет ситуацию. 
Таблица 1. Численность пенсионеров и средний размер назначенных пенсий по видам пенсионного обеспечения и категориям пенсионеров в российской федерации по постоянию на 1 января

\begin{tabular}{|c|c|c|c|c|c|c|c|c|}
\hline & 2013 & 2014 & 2015 & 2016 & 2017 & 2018 & 2019 & 2020 \\
\hline $\begin{array}{l}\text { Численность пенсионеров, } \\
\text { состоящих на учете в системе } \\
\text { Пенсионного фонда Российской } \\
\text { Федерации, тыс. человек }\end{array}$ & 40573 & 41019 & 41456 & 42729 & 43177 & 43504 & 43865 & 43456 \\
\hline \multicolumn{9}{|l|}{ из них получающие пенсии: } \\
\hline по старости & 33451 & 33950 & 34422 & 35555 & 36003 & 36336 & 36710 & 36341 \\
\hline по инвалидности & 2490 & 2410 & 2317 & 2267 & 2183 & 2107 & 2043 & 2088 \\
\hline $\begin{array}{l}\text { по случаю потери кормильца } \\
\text { (на каждого нетрудоспособного } \\
\text { члена семьи) }\end{array}$ & 1362 & 1344 & 1331 & 1395 & 1405 & 1408 & 1403 & 1381 \\
\hline $\begin{array}{l}\text { пострадавшие в результате } \\
\text { радиационных и техногенных } \\
\text { катастроф и члены их семей }\end{array}$ & 298 & 302 & 312 & 332 & 382 & 422 & 443 & 459 \\
\hline $\begin{array}{l}\text { Федеральные государственные } \\
\text { гражданские служащие }\end{array}$ & 62 & 66 & 66 & 71 & 68 & 74 & 77 & 78 \\
\hline Социальные & 2909 & 2946 & 3007 & 3108 & 3134 & 3156 & 3188 & 3198 \\
\hline $\begin{array}{l}\text { Средний размер пенсии } \\
\text { пенсионеров, состоящих } \\
\text { на учете в системе } \\
\text { Пенсионного фонда } \\
\text { Российской Федерации }{ }^{2}, \\
\text { рублей }\end{array}$ & 9153,6 & 10029,7 & 10888,7 & 12080,9 & 12425,6 & 13323,1 & 14102,1 & 14904,4 \\
\hline \multicolumn{9}{|l|}{ из них получающие пенсии: } \\
\hline по старости & 9790,1 & 10716,4 & 11569,1 & 12830,4 & 13172,5 & 14151,6 & 14986,3 & 15878,4 \\
\hline по инвалидности & 6106,3 & 6669,2 & 7209,9 & 8040,1 & 8253,7 & 8807,4 & 9278,6 & 9823,9 \\
\hline $\begin{array}{l}\text { по случаю потери кормильца } \\
\text { (на каждого нетрудоспособного } \\
\text { члена семьи) }\end{array}$ & 5959,0 & 6598,6 & 7185,1 & 7924,9 & 8175,7 & 8875,7 & 9479,2 & 10109,9 \\
\hline $\begin{array}{l}\text { пострадавшие в результате } \\
\text { радиационных и техногенных } \\
\text { катастроф и члены их семей }\end{array}$ & 8402,6 & 8639,2 & 9779,2 & 10766,7 & 11261,1 & 11863,2 & 12428,5 & 12997,1 \\
\hline $\begin{array}{l}\text { Федеральные государственные } \\
\text { гражданские служащие }\end{array}$ & 12422,9 & 14020,1 & 15550,0 & 17186,4 & 17500,8 & 18709,7 & 19994,1 & 21224,3 \\
\hline Социальные & 5919,0 & 6446,4 & 7548,3 & 8302,4 & 8644,4 & 8806,6 & 9093,7 & 9298,1 \\
\hline
\end{tabular}

По данным Пенсионного фонда Российской Федерации.

1 В 2017 г. данные приведены не включая единовременную денежную выплату, назначенную в соответствии с Федеральным законом от 22 ноября 2016 г. № 385-Ф3 в размере 5 тысяч рублей [1]

Конечно, любая патология, протекающая в пожилом возрасте, имеет ряд особенностей, которые объясняются и наличием общесоматической патологии, зачастую не одной, неспецифической клинической картиной, трудно прогнозируемым течением и часто быстрым прогрессированием болезни, а также высоким процентом осложнений и целесообразностью дальнейших реабилитационных мероприятий.

Был проведен анализ выполненных работ пациентов, обратившихся за медицинской помощью в стоматологическое отделение районной больницы за 2019 год и первый квартал 2020 года. За это время было принято 80 па- циентов, являющихся пенсионерами. Из них в плановом порядке - 28, по мере обращения - 52. Возраст пациентов варьировался от 55 до 87 лет. На момент лечения все пациенты находились в удовлетворительном состоянии, обострения имеющихся хронических заболеваний не наблюдалось.

В ходе опроса обследуемых респондентов, выяснилось, что большинство пациентов выбирают удаление зуба вместо лечения. Объем и качество оказанной хирургической помощи напрямую влияет на формирование условий в полости рта для дальнейшего протезирования. 
Таблица 2. Доля лиц в возрасте 55 лет, получивших амбулаторно-поликлиническую помощь (по итогам Комплексного наблюдения условий жизни населения, в процентах) [1]

\begin{tabular}{|c|c|c|c|c|}
\hline & \multicolumn{4}{|c|}{ Все респонденты } \\
\hline & 2011 & 2014 & 2016 & 2018 \\
\hline $\begin{array}{l}\text { Лица в возрасте } 55 \text { лет и более, обращавшиеся за амбулаторно- } \\
\text { поликлинической помощью в медорганизации - всего }\end{array}$ & 100 & 100 & 100 & 100 \\
\hline $\begin{array}{l}\text { из них получили медицинскую помощь при последнем обращении } \\
\text { в медицинскую организацию }\end{array}$ & 97,6 & 96,6 & 96,6 & 96,9 \\
\hline $\begin{array}{l}\text { Мужчины в возрасте } 55 \text { лет и более, обращавшиеся за амбулаторно- } \\
\text { поликлинической помощью в медорганизации - всего }\end{array}$ & 100 & 100 & 100 & 100 \\
\hline $\begin{array}{l}\text { из них получили медицинскую помощь при последнем обращении } \\
\text { в медицинскую организацию }\end{array}$ & 97,6 & 96,7 & 97,0 & 96,8 \\
\hline $\begin{array}{l}\text { Женщины в возрасте } 55 \text { лет и более, обращавшиеся за амбулаторно- } \\
\text { поликлинической помощью в медорганизации - всего }\end{array}$ & 100 & 100 & 100 & 100 \\
\hline $\begin{array}{l}\text { из них получили медицинскую помощь при последнем обращении } \\
\text { в медицинскую организацию }\end{array}$ & 97,7 & 96,6 & 96,4 & 97,0 \\
\hline \multicolumn{5}{|l|}{$\begin{array}{l}\text { ДОЛЯ ЛИЦ В ВОЗРАСТЕ } 55 \text { ЛЕТ, ПОЛУЧИВШИХ СТОМАТОЛОГИЧЕСКУЮ ПОМОЩЬ } \\
\text { (по итогам КомпЛеКсного наблюдения условий жизни населения, в процентаХ) }\end{array}$} \\
\hline & \multicolumn{4}{|c|}{ Все респонденты } \\
\hline & 2011 & 2014 & 2016 & 2018 \\
\hline $\begin{array}{l}\text { Лица в возрасте } 55 \text { лет и более, обращавшиеся за стоматологической } \\
\text { помощью в медорганизации - всего }\end{array}$ & 100 & 100 & 100 & 100 \\
\hline из них получили стоматологическую помощь при последнем обращении & 96,1 & 91,9 & 90,0 & 90,3 \\
\hline $\begin{array}{l}\text { Мужчины в возрасте } 55 \text { лет и более, обращавшиеся за стоматологической } \\
\text { помощью в медорганизации - всего }\end{array}$ & 100 & 100 & 100 & 100 \\
\hline из них получили стоматологическую помощь при последнем обращении & 96,9 & 92,3 & 90,9 & 90,4 \\
\hline $\begin{array}{l}\text { Женщины в возрасте } 55 \text { лет и более, обращавшиеся за стоматологической } \\
\text { помощью в медорганизации - всего }\end{array}$ & 100 & 100 & 100 & 100 \\
\hline из них получили стоматологическую помощь при последнем обращении & 95,7 & 91,6 & 89,5 & 90,2 \\
\hline
\end{tabular}

В силу физиологических особенностей, у лиц пожилого возраста заживление лунки, в большинстве случаев, характеризуется затяжным течением. В послеэкстрационных областях, зачастую, регистрируется неравномерная атрофия костной ткани, что негативно сказывается на последующем ортопедическом лечении. $[2,3]$ Тем не менее, в 89\% случаев пациенты нуждались в санации полости рта перед протезированием, причем в большинстве случаев было целесообразно и терапевтическое и хирургическое лечение.

По итогу проведенной работы было сдано 289 зубных протезов, из которых искусственных коронок - 135, мостовидных протезов - 36, ч/с пластиночных протезов - 56, п/с пластиночных протезов - 62 .
Период адаптации к новым зубным протезам в 73\% случаев прошел достаточно быстро, не принося выраженного дискомфорта пациенту.

Опрос, проведенный после завершения лечения, показал, что большая часть пациентов, а это 96\% обследуемых, удовлетворена оказанной помощью.

Однако, проведенное в ходе лечения анкетирование выявило серьезную стоматологическую неграмотность пациентов пенсионного возраста. Выяснилось, что регулярно (т.е. 2 раза в день) зубы чистит только $24 \%$ опрошенных. Порядка 48\% утверждает, что чистит зубы утром ежедневно. И 28\% пациентов заявило, что чистит зубы несколько раз в неделю или реже. Врача-стомато- 
лога большая часть опрошенных посещает в случае возникновения острых болевых ощущений, а к профилактическому приему относятся достаточно скептически.

Неудовлетворительная гигиена ротовой полости, нерегулярное посещение врача-стоматолога, несвоевременное лечение стоматологических патологий, неграмотный уход за зубными протезами - все это говорит о недостаточном стоматологическом просвещении среди лиц пенсионного возраста.

Ключевой составляющей успешной профилактической или лечебной программы является качественное стоматологическое просвещение населения. В понятие «стоматологическое просвещение» входит мотивация населения в целом и каждого пациента, в частности, к сохранению здоровья, и конечно обучение грамотной гигиене полости рта.

Стоматологическое просвещение - это комплекс мероприятий по предоставлению пациентам любых познавательных материалов, направленных на самооценку и выработку тех привычек и правил поведения, которые максимально исключат развитие факторов риска возникновения и развития стоматологических заболеваний и позволят поддерживать приемлемый уровень стоматологического здоровья. Данный метод профилактики актуален для всех возрастных групп населения. [4] Разумеется, ключевую роль в сохранении стоматологического здоровья играет личная ответственность пациента.

Врачу необходимо сформировать у населения убежденность в необходимости регулярного и качественного ухода за полостью рта с целью предупреждения возникновения стоматологических патологий.

Анкетирование пациентов используется в качестве контроля эффективности стоматологического просвещения. Помимо этого, в просветительской работе активно применяются памятки, брошюры, учебная литература, СМИ и т.д. Найти подход, суметь убедить пациента пенсионного возраста в необходимости пересмотреть свои привычки по уходу за полостью рта - долгий и непростой процесс. Как правило, мероприятия подобного рода идут медленно, и зачастую результаты быстро обратимы. Чтобы процесс обучения проходил успешно требуется участие многих специалистов, таких как врачи-стоматологи и врачи других узких специальностей, работающих с пациентом, психологи и педагоги.

Одной из причин неграмотности населения в вопросе стоматологического здоровья является тот факт, что в нашей стране в последние годы санитарно-просветительская работа носит достаточно формальный характер, что в итоге становится причиной роста стоматологической заболеваемости.

Разумеется, основная нагрузка по просвещению населения в вопросах стоматологической заболеваемости лежит на врачах-стоматологах. Необходимо регулярно разрабатывать новые информационные материалы, проводить беседы, оформлять краткие рекомендации в виде брошюр и листовок, чтобы информация всегда была у пациента «на руках». Мотивировать взрослое население достаточно трудная задача, особенно если речь идет о людях пенсионного возраста. Многие пациенты этой группы считают, что их навыков и знаний достаточно. Перед врачом стоит нелегкая задача грамотно и аргументировано провести беседу с пациентом и убедить его в перемене своих привычек по уходу за ротовой полостью. Чтобы увидеть положительную динамику по улучшению стоматологического здоровья населения, необходима не только качественная работа специалистов, но и общества в целом. В обществе важно сформировать мнение о необходимости контроля за состоянием полости рта, как и за здоровьем в целом.

Требуется приложить максимум усилий для мотивации населения сохранять стоматологической здоровье, причем данная тенденция должна иметь долговременный характер. При работе с пациентом, врач регулярно должен учитывать важность санитарно-просветительской работы в профилактике и лечении стоматологических заболеваний.

\section{ЛИТЕРАТУРА}

1. Федеральная служба государственной статистики. Официальный сайт. [Электронный ресурс] — Режим доступа. www.gks.ru

2. Лосев Ф.Ф. Экспериментально клиническое обоснование использования материалов для напрвленной регенерации челюстной костной тканипри ее атрофии и дефектах различной этиологии/ Ф. Ф. Лосев: автореферат дис. Д-ра мед. Наук. М.с.— 2002.— С. 165.

3. Каливарджиян Э. С. Разработка пористых эластичных композиций дл двухслойных пластиночных протезов / Э. С. Каливарджиян, Н. А. Голубев, В.В. калмыков // Актуальные вопросы ортопедической стоматологии: сб. научных трудов. Воронеж: ВГМА, 2000

4. Г.М. Флейшер Стоматологическое просвещение населения / Монография — 2019.

( З Зубкова Татьяна Владимировна ( tatjana-zubkova00@yandex.ru ).

Журнал «Современная наука: актуальные проблемы теории и практики» 